\title{
Sustentabilidade, agricultura familiar e políticas públicas no Brasil: Uma revisão de
}

\section{literatura}

\author{
Sustainability, family farming and public policies in Brazil: a literature review \\ Sostenibilidad, agricultura familiar y políticas públicas en Brasil: una revisión bibliográfica
}

Recebido: 24/03/2021 | Revisado: 30/03/2021 | Aceito: 08/04/2021 | Publicado: 11/04/2021

\author{
Leonardo França da Silva \\ ORCID: https://orcid.org/0000-0002-9710-8100 \\ Universidade de Federal Viçosa, Brasil \\ E-mail: leonardo.silva@ufv.br \\ Marcos Antônio Pereira da Fonseca Maltez \\ ORCID: https://orcid.org/0000-0003-0941-8051 \\ Universidade Federal Rio Grande do Sul, Brasil \\ E-mail: marcos.maltez@biocitrus.com.br \\ Carlos Eduardo Alves Oliveira \\ ORCID: https://orcid.org/0000-0002-2104-7428 \\ Universidade de Federal Viçosa, Brasil \\ E-mail: carloseoliveira@ufv.br \\ Yara Janaína Pinto Gusmão \\ ORCID: https://orcid.org/0000-0002-4134-303X \\ Universidade Federal de Minas Gerais, Brasil \\ E-mail: yaragus10@ hotmail.com \\ Maria Angela de Souza \\ ORCID: https://orcid.org/0000-0002-1061-3340 \\ Universidade de Federal Viçosa, Brasil \\ E-mail: maria.a.souza@ufv.br \\ João Antônio Costa do Nascimento \\ ORCID: https://orcid.org/0000-0001-5984-5997 \\ Universidade de Federal Viçosa, Brasil \\ E-mail: jacostadonascimento@gmail.com \\ Charles Paranhos de Oliveira \\ ORCID: https://orcid.org/0000-0001-7692-1648 \\ Universidade de Federal Viçosa, Brasil \\ E-mail: charles.paranhos@ufv.br \\ Osmar de Carvalho Bueno \\ ORCID: https://orcid.org/0000-0003-0666-090X \\ Universidade Estadual Paulista, Brasil \\ E-mail: osmar.bueno@unesp.br
}

\begin{abstract}
Resumo
O presente estudo objetiva analisar a literatura relacionada à sustentabilidade na agricultura familiar e a aplicação em políticas públicas brasileiras. Para isso, foi realizada uma análise de artigos relacionados ao tema, destacando-se os principais tópicos, além de dados secundários do Governo Federal. Por meio das informações coletadas, observou-se a existência de políticas públicas voltadas para a alimentação (escolar e da população) e comercialização, evidenciandose canais institucionais para o escoamento dos alimentos produzidos por estes. A sustentabilidade nesses sistemas produtivos também denota ser uma característica diferenciadora, considerando os impactos positivos ao ambiente, pelo reaproveitamento de resíduos visando à fertilidade do solo e as possibilidades criadas em termos de geração de renda para as famílias agricultoras.
\end{abstract}

Palavras-chave: Produção sustentável; Mercados institucionais; Sistemas alimentares.

\begin{abstract}
The present study aims to analyze the literature related to sustainability in family farming and its application in Brazilian public policies. To this end, an analysis of articles related to the theme was conducted, highlighting the main topics, in addition to secondary data from the Federal Government. Through the information collected, it was observed the existence of public policies aimed at food (school and population) and marketing, highlighting institutional channels for the distribution of food produced by these. Sustainability in these production systems also denotes a differentiating characteristic, considering the positive impacts on the environment, the reuse of waste aimed at soil fertility and the possibilities of generating income for farming families.
\end{abstract}

Keywords: Sustainable production; Institutional markets; Food systems. 


\begin{abstract}
Resumen
El presente estudio tiene como objetivo analizar la literatura relacionada con la sostenibilidad en la agricultura familiar y su aplicación en las políticas públicas brasileñas. Para ello, se realizó un análisis de los artículos relacionados con el tema, destacando los principales temas, además de datos secundarios del Gobierno Federal. A través de la información recolectada, se observó la existencia de políticas públicas enfocadas a la alimentación (escolar y poblacional) y a la comercialización, evidenciando canales institucionales para la distribución de los alimentos producidos por ellos. La sostenibilidad en estos sistemas de producción también denota una característica diferenciadora, teniendo en cuenta los impactos positivos en el medio ambiente, la reutilización de los residuos destinados a la fertilidad del suelo y las posibilidades de generar ingresos para las familias campesinas.
\end{abstract}

Palabras clave: Producción sostenible; Mercados institucionales; Sistemas alimentarios.

\title{
1. Introdução
}

Há várias modelos de agricultura no mundo, todas atreladas, em especial, a um conjunto de valores sociais, econômicos e culturais. Elas caracterizam a identidade e os costumes da região, de uma maneira específica. A agricultura, de modo geral, é caracterizada pela produção de alimentos, fibras, combustíveis e, colateralmente, à produção de resíduos orgânicos. No final do século XX, observou-se a necessidade do fortalecimento de uma agricultura menos degradante, com maior eficiência, geradora de trabalho e renda, que visasse qualidade de vida e dignidade das pessoas que vivem no campo. O modelo convencional de agricultura, disseminado após a "revolução verde", tinha como foco a modernização do campo, com a adesão dos pacotes tecnológicos, o que ocasionou um aumento expressivo da produtividade, resultando em significativos impactos, dentre eles os de cunho ambiental e social (Grisa \& Schimitt, 2011; Perez-Cassarino, 2013; Soriano, 2010). Dentro da esfera ambiental, acarretou a redução da biodiversidade, a degradação do solo, a contaminação e a escassez dos recursos hídricos. Além disto propiciou o surgimento do risco causado pela intensificação dos produtos químicos, que afetam o meio ambiente, o trabalhador rural, como também, os seus consumidores (Altieri, 2012; Soriano, 2010).

No que diz respeito à questão social, ocorreu, entre outros, a exclusão dos pequenos produtores, em razão dos elevados custos dos insumos e maquinários exigidos pela adesão de pacote tecnológico utilizado para o manejo eficiente das grandes culturas, desencadeando aumento da pobreza no campo e, consequentemente, êxodo rural (Salton et al., 2005; Neder, 2014; Goodman, 2017). O novo modelo agrícola traz consigo as preocupações ambientais, o que ocasiona na busca por uma agricultura menos degradante e mais sustentável. De acordo com “Agenda 21", resultado da ECO 92 (Conferência das Nações Unidas Sobre o Meio Ambiente e o Desenvolvimento, 1992), alertou-se que, para o desenvolvimento sustentável ser atingido, compete com uma crescente demanda por produtos agrícolas, a necessidade de competitividade frente ao mercado internacional e processo produtivo como todo, que vise de maneira simultânea favorecer os indicadores econômicos, ecológicos, sociais e ambientais em um longo prazo (Oliveira, 2007; Guimarães, 1998, Santos \& Cândido, 2013).

Tendo em vista o aprimoramento do conceito de desenvolvimento sustentável, o qual foi difundido a partir da Conferência das Nações Unidas sobre Meio Ambiente e Desenvolvimento, Rio-92, foi colocado em pauta a forma e o comportamento que os seres humanos deveriam lidar com o meio ambiente e assim reformular e inserir novas políticas de desenvolvimento sustentável (Dias, 2011). Do ponto de vista prático do conceito de sustentabilidade, tem-se a exigência de pensar em novas formas de aferir o crescimento e de permitir que exista um processo que possa ser coerente e participativo nas tomadas de decisões e na busca pelo desenvolvimento sustentável (Siqueira, 2001; Silva, 2007). Ao se levar em consideração a temática agrícola e as ideias expostas acima, desponta a necessidade de se fazer alterações significativas no uso da terra, com a busca por sistemas produtivos sustentáveis, que realmente atendam seus três principais aspectos: ambiental, econômico e social (Bianco, 2016; Romeiro, 2012, Siqueira, 2001; Dias, 2011).

A partir disto, Rabelo e Lima (2007), Martins (2008), e Guimarães (1998), enfatizam a formulação de um conjunto de indicadores, visando aferir as comunidades, sobre as possíveis ameaças e tendências sobre o desenvolvimento sustentável, constituindo uma espécie de carta de navegação sobre as tendências futuras, na qual se vislumbra um destino, se acompanha 
um trajeto, se corrigem os rumos. A utilização de indicadores desponta como ferramenta essencial para a gestão e avaliação da sustentabilidade. E, no caso específico do presente trabalho, a definição de indicadores confiáveis e quantificáveis representa um instrumento fundamental e estratégico para avaliação do desempenho do agroecossistemas, com a finalidade de melhorar os níveis de sustentabilidade (Silva, 2007; Dias, 2011; Guimarães,1998).

No Brasil, as discussões com enfoque no tema da sustentabilidade têm ganhado notoriedade, principalmente após a ascensão do modelo agrícola convencional, que fez surgir inúmeros questionamentos sobre a exequibilidade desse modelo em um maior espaço de tempo. Esse discurso contestador teve maior impacto especialmente no campo da agricultura familiar, no qual os reflexos da modernização do campo foram mais vastos (Stoffel \& Colognese, 2015; Costa et al., 2015; Zanelli et al., 2015). Entende-se que a agricultura familiar tem fundamental importância dentro do cenário agrícola brasileiro, haja vista que 85\% dos estabelecimentos brasileiros são pertencentes a grupos familiares (Del Fiori, 2017). O mesmo fato se confirma com os dados fornecidos pela Secretária de Agricultura Familiar e Desenvolvimento Agrário (2017), que revela que são 13,8 milhões de pessoas que vivem em 4,1 milhões de estabelecimentos familiares, o que corresponde com 77\% da população que vive no campo.

Por outro lado, a agricultura familiar tem grande participação nos produtos que formam a cesta básica de alimentação. Destacam-se nessa área a produção de mandioca (87\%); feijão (70\%); milho (46\%); café (34\%); arroz (34\%); trigo (21\%); leite (58\%); aves (50\%); suínos (59\%); e bovinos (30\%) (IBGE, 2006). No estado de São Paulo, constata-se a importância do padrão de produção familiar na oferta de relevantes produtos agrícolas (IBGE, 2006).

É importante destacar que a agricultura familiar tem enfrentado de modo especial, problemas relacionados à insuficiência da assistência técnica e de gestão na coordenação dos programas governamentais para o setor; ademais, o pouco nível de organização por parte dos produtores, fazendo com que o desenvolvimento sustentável em áreas rurais não obtenha índices satisfatórios (Santos \& Cândido, 2013, Oliveira, 2007; Del Fiori, 2017). Partindo do exposto, o objetivo desta revisão de literatura foi realizar um levantamento de aspectos socioambientais, políticas públicas e sua importância da agricultura familiar para a produção e abastecimento brasileiro, à luz das teorias acadêmicas e dos investimentos governamentais.

\section{Metodologia}

Esse estudo foi elaborado com base na sistematização de estudos referente à agricultura familiar, sustentabilidade e políticas públicas, sendo, portanto, configurado como de natureza qualitativa (Pereira et al., 2018). Os estudos aqui utilizados foram levantados a partir de bibliotecas virtuais, periódicos e dados governamentais secundários, obtidos em portais do Governo Federal do Brasil, visando elucidar o tema pesquisado. Dessa maneira, foi realizado uma análise das informações coletadas, observando-se os principais tópicos referentes a sustentabilidade na agricultura familiar, e a aplicação em políticas públicas no país.

\section{Resultados e Discussão}

\section{Agricultura Familiar: Conceito e Discussão}

A definição da agricultura familiar é muito complexa, levando em consideração vários fatores, tais como: tamanho da propriedade agrícola, modo de organização de trabalho das famílias, gestão e mão de obra do estabelecimento. Conforme a Lei $\mathrm{n}^{\mathrm{o}} 11.326$ de 2006, que estabelece diretrizes para a Política Nacional da Agricultura Familiar e Empreendimentos Familiares Rurais, a caracterização da agricultura familiar se apresenta da seguinte forma:

Art. $3^{\circ}$. Para os efeitos desta Lei, considera-se agricultor familiar e Empreendedor familiar rural aquele que pratica atividades no meio rural, atendendo, simultaneamente, aos seguintes requisitos: 
I - Não detenha, a qualquer título, área maior do que 4 (quatro) módulos fiscais; II - utilize predominantemente mão de obra da própria família nas atividades econômicas do seu estabelecimento ou empreendimento; III - tenha renda familiar predominantemente originada de atividades econômicas vinculadas ao próprio estabelecimento ou empreendimento; IV - dirija seu estabelecimento ou empreendimento com sua família (Brasil, 2006).

Esta definição normativa da agricultura familiar é importante, dada a relevância da agricultura familiar para o país. Segundo dados do último Censo Agropecuário (IBGE, 2017), divulgado no ano de 2019, existem 5.073.324 estabelecimentos de agricultores familiares, os quais ocupam cerca de 351,289 milhões de ha, cerca de $41 \%$ da área total do país. É importante destacar ainda que, de cada dez empregos gerados no campo, sete são oriundos de atividades ligadas à agricultura familiar. Finalmente, a maior parte da alimentação dos brasileiros vem da agricultura familiar, sendo esta fundamental na manutenção da segurança alimentar da nação (Ortega, 2008; IBGE, 2017).

Como não se bastasse a eficiência da agricultura familiar, a criação de ocupações produtivas, o valor por hectare e a contribuição com a alimentação do país é superior às contribuições do agronegócio. Mesmo que ocupando uma área relativamente menor, os estabelecimentos familiares respondem por 38\% do valor total da produção, apresentando maior produtividade. Por fim, a ocupação da mão de obra da agricultura familiar tem uma maior efetividade e participação, respondendo por 15 pessoas trabalhando a cada 100 ha (Del Grossi, 2010, Gusmão, 2019).

O Censo Agropecuário referente ao ano de 2006 mostra que, além da produção de alimentos, a agricultura familiar também se sobressai na produção de produtos não alimentícios. No estudo, é revelado que os estabelecimentos familiares ocupam posição de destaque na participação nos recursos gerados pela comercialização de húmus (64\%), artesanato e tecelagem (57\%), produtos da agroindústria (49\%) e prestação de serviços (47\%)” (IBGE, 2006).

$\mathrm{O}$ agricultor familiar tem um papel fundamental no setor agropecuário brasileiro. Ainda segundo dados do censo agropecuário de 2006, quando se trata da produção de alimentos básicos, como feijão, arroz, milho, mandioca e hortaliças, a agricultura familiar chega a responder por $70 \%$ da produção nacional. Dentre as cadeiras produtivas em que a agricultura familiar tem elevada participação, destacam-se as produção de mandioca (Manihotesculenta) - 87\%; feijão (Phaseolusvulgaris) - 70\%; milho (Zeamays) - 46\%; café (Coffea) - 34\%; arroz (Oryza sativa) $-34 \%$; trigo (Triticum) - 21\%; leite- 58\%; aves - 50\%; suínos - 59\%; e bovinos - 30\% (IBGE, 2006).

Deste modo, a agricultura familiar se consolidou na última década como maior responsável pela garantia da segurança alimentar do país, principalmente em relação a produtos de consumo no mercado interno. Considera de fundamental importância para o desenvolvimento econômico das cidades, para a produção de alimentos e para a redução do êxodo rural, além de utilizar durante o processo produtivo, práticas ecologicamente mais equilibradas (Padua et.al., 2013; Grisa et al., 2011; Silva \& Ferreira, 2016; Souza-Esquerdo \& Bergamasco, 2015).

Apesar de se apresentar como um segmento de grande importância para o desenvolvimento e segurança alimentar do país, a agricultura familiar durante muito tempo foi inferiorizada e mantida a margem da formulação de políticas públicas. Este cenário começou a ser alterado a partir da mobilização de organizações de agricultores familiares, que culminaram com a conquista, a partir do ano de 1996, do Programa Nacional de Fortalecimento da Agricultura Familiar (PRONAF). A partir de então, observa-se que a agricultura familiar vem ganhando força, por meio de investimentos governamentais - políticas públicas (Grisa et al., 2011).

Ante todo o exposto, observa-se que a agricultura familiar, além de ser um instrumento de geração de renda no campo, também gera ocupação e promove o crescimento cada vez maior do setor rural no Brasil, garantindo a segurança alimentar e nutricional de muitos brasileiros. Todavia, faltam políticas objetivando especificamente o escoamento e comercialização da produção da agricultura familiar com preço justo, bem como apoio ao fortalecimento da agricultura familiar (Grisa; Zimmermann, 2015; Silva \& Ferreira, 2016). 


\section{A sustentabilidade e o desenvolvimento sustentável}

O conceito de sustentabilidade, ou desenvolvimento sustentável, embora utilizado de forma ampla nas duas últimas décadas, se apresenta como algo em permanente construção. A origem do termo desenvolvimento sustentável se deu na década de 1980, a partir de estudos da Organização das Nações Unidas (ONU) sobre as mudanças climáticas, como resposta para a humanidade, diante da crise social e ambiental pela qual o mundo passava desde a segunda metade do século XX. Na segunda metade dessa década, surgiu o mais conhecido e disseminado conceito sobre Desenvolvimento sustentável (Barbosa, 2008).

[...] desenvolvimento sustentável é um processo de transformação no qual a exploração dos recursos, a direção dos investimentos, a orientação do desenvolvimento tecnológico e a mudança institucional se harmonizam e reforça o potencial presente e futuro, a fim de atender às necessidades e aspirações futuras [...] é aquele que atende às necessidades do presente sem comprometer a possibilidade de as gerações futuras atenderem as suas próprias necessidades (Nosso Futuro Comum, 1988, p. 46).

Sachs (2009), Moldan et. al. (2012), e Garcia (2011), enfatizam que, de qualquer modo, a sustentabilidade é um termo que tem sua origem ligada à agricultura, classificando-se como uma palavra dinâmica, uma vez que busca manter a capacidade de reposição de uma população, ou seja, manter a biodiversidade de um ecossistema, tendo uma preocupação com as gerações presentes e futuras.

Lindsey (2011) e Stepanyan et. al. (2013) afirmam que, embora os termos sustentabilidade e desenvolvimento sustentável, sejam muito utilizados na literatura científica, inexiste, atualmente, um conceito tido como "concreto" e "universal". Apesar dos conceitos e termos trazerem consigo múltiplas interpretações, a noção de sustentabilidade e desenvolvimento sustentável pode ser compreendida como sobrevivência. Atrelado à sustentabilidade, encontra-se a questão ambiental propriamente dita. $\mathrm{O}$ conceito de meio ambiente é entendido sob forma ordenada, considerando que o ser humano não é só consumidor na cadeia trófica, mas sim um grande gerador de impactos, muitas vezes incompatíveis com a natureza (Yolles \& Fink, 2014; Sachs, 2009).

Albuquerque Neto et. al. (2008) enfatizam que o debate sobre sustentabilidade precisa deixar de ser teórico, e se tornar operacional. Para que isso seja possível, é necessário, portanto, pensar em uma maneira de quantificar a chamada "sustentabilidade". A identificação da informação relevante, capaz de potencialmente esclarecer a existência de quaisquer processos ditos como não sustentáveis de desenvolvimento na relação entre sociedade e meio ambiente. Isto é algo somente possível para a sociedade se ela dispuser de instrumentos técnicos científicos e políticos construídos com tal finalidade. Em suma, a partir do momento que consegue estimar a sustentabilidade levantada como condição para a construção sustentável e em fase de desenvolvimento.

A partir de tais considerações, os indicadores se tornam essenciais na busca de quantificação da sustentabilidade. Estes são na busca para alcançar o processo de desenvolvimento com bases sustentáveis. Este processo ocorre por intermédio de um conjunto de variáveis, que contempla uma série de informações necessárias para a compreensão da realidade investigada. Para que o desenvolvimento sustentável seja verificado, é necessário visão a longo prazo (Guimarães, 1998, Dias, 2011; Albuquerque Neto et. al., 2008). Deste modo, conclui-se que os indicadores são essenciais, notadamente por permitirem mensurar a distância entre a real situação na qual a sociedade se encontra, e seus objetivos para que ocorra o desenvolvimento estimado (Rabelo \& Lima, 2007; Guimarães, 1998).

\section{Dimensões da Sustentabilidade}

Para Martins (2008) Waquil et al., (2007) e Sachs (2009), para a construção de um modelo de desenvolvimento sustentável eficaz e coerente, é imprescindível o reconhecimento da diversidade da estrutura, por meio das múltiplas 
dimensões da sustentabilidade, e da definição dos objetivos distintos que orientam os modos de vida da sociedade. O termo sustentabilidade, de modo geral, denota na maioria das vezes expressões voltadas às questões ambientais propriamente ditas. Todavia, Sachs (2009) argumenta que é um termo amplo, que envolve diversas dimensões, como social, econômica e política, as quais podem ser representadas pelo ambiente institucional. Contudo, para que ocorra o desenvolvimento sustentável, teoricamente deveria existir o equilíbrio entre as três dimensões da sustentabilidade. A dimensão econômica é a mais abordada nas avaliações dos ecossistemas, devido o seu elevado peso relativo nas decisões humanas, merecendo, portanto, um destaque (Garcia, 2011).

De acordo com Sachs (2009), a vertente econômica deve focar no desenvolvimento econômico intersetorial equilibrado, devendo ainda primar pela segurança alimentar, capacidade de modernização contínua dos instrumentos de produção, diversificação dos produtos e mercados, e garantia na geração de renda. Para o autor, a condição econômica deve ser vista como necessária, mas não condição prévia das outras dimensões, uma vez que o desequilíbrio econômico pode levar à ocorrência de transtornos sociais capazes de desencadear insustentabilidade ambiental.

No que tange a dimensão social, deve-se manter um patamar de homogeneidade em relação a distribuição de justa de renda, geração de empregos, qualidade de vida e acesso aos recursos e serviços (Sachs, 2009). Esta dimensão deve estar posicionada a frente das demais, devido ser primordial a finalidade do desenvolvimento, pois há maiores chances de que um colapso social ocorrer antes de uma tragédia ambiental. A dimensão política ou institucional está ligada ao compromisso do Estado em assegurar e programar políticas e projetos que busquem atingir o desenvolvimento social. Ela tem o papel de protagonizar o processo de reconciliação e equilíbrio entre forças que ocasionam a busca pelo desenvolvimento e conservação da biodiversidade (Sachs, 2009).

\section{Sustentabilidade na agricultura familiar: Uma aproximação a partir do conceito de agrossistema}

O Princípio de resiliência é utilizado por Souza Filho (2001) para definir sustentabilidade em um agrossistema. O autor enfatiza que sustentabilidade é definida como a capacidade de manter a produtividade, quando o dado agrossistema é exposto a forças "perturbadoras", classificadas como "stress e choque". O resultado de um "stress" pode se apresentar como pouco significativo no curto prazo, mas ocasionar efeitos destrutivos, e muitas vezes irreversíveis, a longo prazo. Os principais danos causados pelo "stress" são contaminação do solo e recursos hídricos, ocorrência de processos de erosão e salinização, e aumento do preço dos produtos agrícolas. Já o "choque" é um evento imprevisível e transitório, como a ocorrência de pestes, seca, inundações, fortes elevações nos preços de insumos, entre outros.

$\mathrm{O}$ autor defende ainda que, para atingir o desenvolvimento sustentável em um agrossistema, é preciso que se leve em consideração quatro critérios básicos: sustentabilidade, produtividade, estabilidade e equidade. Produtividade é definida como produção por área, enquanto estabilidade é a manutenção ou aumento dessa produtividade diante de distúrbios que possam ocorrer. Já equidade refere-se a justa distribuição da produtividade entre os indivíduos envolvidos no sistema agrícola. O equilíbrio, quarta variável, é a manutenção dessas três variáveis, que determinam a sustentabilidade do sistema.

Portanto, o debate sobre como alcançar sustentabilidade na agricultura é problematizado por disputas e discordâncias, no que diz respeito a quais elementos da produção são aceitáveis e quais não são. Algumas tecnologias agrícolas, tidas como sustentáveis no mercado de insumos, podem não ser sustentáveis na propriedade agrícola. A utilização de dejetos de suínos e aves, por exemplo, muito empregada em pequenas propriedades em substituição a adubos químicos, é tida como sustentável. Porém, o seu uso excessivo pode comprometer o lençol freático local. Da mesma forma, a agricultura orgânica é amplamente aceita como sustentável, mas deixa de ser com a prática da monocultura orgânica (Souza Filho, 2001).

Neves e Castro (2010) argumentam que, dada a preocupação mundial crescente com o conceito de sustentabilidade, a inserção da agricultura familiar em subsistemas coordenados será mais valorizada pelo fato desse segmento fortalecer as 
opções ambientais e socialmente corretas, além de economicamente viáveis e institucionalmente amparadas, respondendo a uma pressão da sociedade na busca por modelos de produção sustentáveis. Assim, colocam a abrangência dessa visão da seguinte forma:

O mais interessante de tudo é que não se abordarão apenas produtos, mas sistemas de produção ambientalmente corretos. Tratar-se-á de outro fenômeno ocorrido nos últimos dez anos que foi a transição do foco apenas no meio ambiente para um foco mais abrangente, mais subjetivo e mais complicado, do qual o meio ambiente faz parte, chamado sustentabilidade. Para muitos consumidores não basta apenas o produto ser verde. O modo de produção deve ser sustentável (Neves \& Castro, 2010, p. 3).

Os autores destacam que a agricultura familiar apresenta melhores condições de sustentabilidade pelo fato de incorporar estratégias de equilíbrio entre os parâmetros econômicos, sociais e ambientais, amparados pelo ambiente institucional. O estabelecimento familiar se caracteriza em uma unidade de produção e consumo, que valoriza, dessa forma, a diversidade, os policultivos, distribuídos de forma equilibrada no espaço e no tempo.

É válido lembrar que, de acordo com Brandenburg (1999), apesar dos diversos contratempos econômicos enfrentados nos últimos anos, os agricultores familiares apresentam uma excepcional capacidade de adaptação, fruto da sua "habilidade" de resistir ao "jogo" dialético do sistema hegemônico capitalista. Desta forma, a partir das últimas décadas, várias estratégias passaram a ser incorporadas nos trabalhos que visam a sustentabilidade da agricultura familiar. Estas se resumem em um único termo, frequentemente utilizado para englobar várias práticas de agricultura sustentável, qual seja agricultura alternativa.

\section{Políticas públicas e agricultura familiar: um breve relato Histórico}

Segundo o Instituto de Pesquisa Econômica Aplicada (2010), o início da intervenção do estado brasileiro na economia buscando o fortalecimento da economia e desenvolvimento se deu no governo de Getúlio Vargas, na década de 1930. Nesta época, foram adotadas diversas estratégias com foco na promoção da industrialização, e consistiam basicamente na substituição de importações, favorecendo a produção de produtos nacionais industrializados, e promovendo mudanças socioeconômicas (IPEA, 2010). Para Delgado e Romano (1999), estas mudanças se deram a partir do contexto da crise internacional de 1929, em que se incentivou a produção interna, como de reduzir a dependência de insumos externos. Os autores destacam que a construção de um mercado interno e o início da industrialização foram maneiras de reduzir as importações. Ao mesmo tempo, ocorria a expansão urbana e industrial, e isso elevou a demanda de produtos alimentícios.

Neste contexto, a modernização conservadora da agricultura no Brasil ocorreu movida por políticas governamentais. No período de 1930 a 1949, ocorreu a regionalização das políticas agrícolas, com consequente aumento da produção, alcançado por meio da federalização dos fomentos e da defesa dos segmentos rurais organizados. Houve ainda uma expansão urbana e industrial, elevando a demanda de produtos rurais (Szmrecsanyi \& Ramos, 1997).

Delgado (1997) relata que até o início da década de 1960, com a ausência de tecnologias industriais no processo produtivo, a produção de alimentos no Brasil foi suficiente para atender somente a demanda do meio urbano. O campo não havia adotados as tecnologias industriais na produção, e os cenários sociais e econômicos do meio rural nesta fase eram marcados por salários muito baixos e concentração fundiária, ao passo que o cenário produtivo era marcado pela utilização de técnicas ainda primárias de produção agrícola.

Ainda para Delgado (1997), neste contexto cresciam os questionamentos sobre a "condição atrasada" da agricultura brasileira, o que desencadeou diversas discussões sobre a atual questão agrária do Brasil. Tal problemática fortaleceu o surgimento de interesses pela reforma agrária, que foi pautada pelos governos até 1964. Este período foi marcado por constantes crises de abastecimento da população urbana, que crescia impulsionada pelo processo de industrialização do país. 
Foi no período entre 1965 e 1980 que, de acordo como Delgado (1997), o Estado brasileiro incorporou técnicas "modernas" na agricultura, levando ao desenvolvimento de uma "agricultura capitalista industrial". O governo estimulou a adoção de pacotes tecnológicos para a agricultura, na chamada "Revolução Verde", e incentivou utilização de linhas de crédito. Para Ribeiro (2010) e Ribeiro (2014), foi neste panorama histórico que as comunidades rurais foram deixadas "de lado" no processo de formulação das políticas pública, sendo muitas das vezes excluídas dos processos de desenvolvimento.

\section{Políticas Públicas voltadas para a comercialização na Agricultura Familiar}

Conforme mencionado anteriormente, as políticas públicas próprias para agricultura familiar começaram a ser estabelecidas no ano de 1996, com surgimento do Programa Nacional de Fortalecimento da agricultura familiar (PRONAF). A partir do PRONAF, os agricultores familiares de fato puderam dispor de forma contundente de uma política pública específica (Dias, 2013).

\section{Programa Nacional de Fortalecimento da Agricultura Familiar (PRONAF)}

No ano de 1996, a agricultura familiar ganhou uma política pública específica, por meio da criação do Programa Nacional de Fortalecimento da Agricultura Familiar (PRONAF). O PRONAF foi estabelecido pela normativa n ${ }^{\circ} 1.946$, de 28 de junho de 1996:

Art. $1^{\circ}$. Fica criado o Programa Nacional de Fortalecimento da Agricultura Familiar - PRONAF, com a finalidade de promover o desenvolvimento sustentável do segmento rural constituído pelos agricultores familiares, de modo a propiciar-lhes o aumento da capacidade produtiva, a geração de empregos e a melhoria de renda (Brasil,1996).

O surgimento do PRONAF se deu pelas reivindicações de movimentos sociais, conjuntamente com sindicatos de trabalhadores rurais, que evidenciaram a importância de se estabelecer diretrizes capazes de fortalecer a produção agrícola de cunho familiar (Dias et al., 2013; Queiroz, 2012). O PRONAF se consagra como a principal política pública de apoio à agricultura familiar, favorecendo muitos municípios brasileiros, notadamente aqueles mais pobres. O principal objetivo do programa é atuar no financiamento de projetos individuais ou coletivos, permitindo a geração de renda aos agricultores. Este conta com menores taxas de juros de financiamentos rurais, e possui as menores taxas de inadimplência, entre todos os sistemas de crédito do país (Queiroz, 2012; Dias et al., 2013; Abramovay \& Veiga,1999).

\section{Programa de Aquisição de Alimentos da Agricultura Familiar (PAA)}

O Programa de Aquisição de Alimentos (PAA) foi criado no ano de 2003, no âmbito do Programa Fome Zero, visava o combate à fome e pobreza no Brasil, e, de maneira conjunta, fortalecer a agricultura familiar. O programa tinha como objetivo a agregação de valor aos produtos oriundos da agricultura familiar, buscando aumentar a renda e a inclusão econômica e social dos agricultores familiares que participaram desta política pública. Dentre os beneficiados com o fornecimento dos produtos estão às crianças de creches e de escolas públicas que realizam a alimentação na escola, pessoas abaixo da linha da pobreza, além de asilos e orfanatos (Brasil, 2012).

\section{Programa Nacional de Alimentação Escolar (PNAE)}

O PNAE teve sua origem em 1940, mas somente em 1988 a promulgação da nova Constituição Federal, foi garantido o direito à alimentação escolar para todos os estudantes do ensino fundamental. A alimentação escolar passou a ser defendida como direito dos estudantes do ensino fundamental e médio (FNDE, 2009). O PNAE caracteriza-se como a política pública mais antiga do país na área de segurança alimentar e nutricional, sendo considerado um dos mais efetivos e de maior 
longevidade na área de alimentação escolar do mundo. O programa contempla assentados da reforma agrária, indígenas, comunidades tradicionais e comunidades quilombolas para realizar a compra de alimentos da Agricultura Familiar, e além de definir um valor por aluno em cada fase estudantil (FNDE, 2009). A política pública PNAE foi a criação por meio da Lei de ${ }^{\circ}$ 11.947, de 2009, que determina:

Do total dos recursos financeiros repassados pelo FNDE, no âmbito do PNAE, no mínimo 30\% (trinta por cento) deverão ser utilizados na aquisição de gêneros alimentícios diretamente da agricultura familiar e do empreendedor familiar rural ou de suas organizações, priorizando-se os assentamentos da reforma agrária, as comunidades tradicionais indígenas e comunidades quilombolas (Brasil, 2009).

Desta forma, o PNAE pode ser considerado uma alternativa de comercialização de produtos e, consequentemente, geração de renda, aos agricultores familiares que participam desta política pública. É importante ressaltar que ainda faltam políticas de incentivo à agricultura familiar no que tange ao escoamento e a venda da produção deste segmento com preço justo (Grisa et. al., 2011; Grisa \& Zimmermann, 2015).

\section{Considerações Finais}

Por meio das fontes consultadas, observa-se o surgimento de experiências consideradas exitosas, no que tange ao desenvolvimento de políticas públicas voltadas para a agricultura familiar no Brasil, ao longo dos anos. A aplicação e o fomento de recursos voltados para a produção e comercialização de alimentação escolar, por exemplo, permitiram promover o escoamento dos produtos oriundos de agricultores familiares, trazendo como benefícios geração de renda aos agricultores familiares, e dieta mais saudável àqueles que utilizam esta alimentação.

Atrelado ao contexto socioeconômico de consumo e estímulo produtivo de alimentos com origem na agricultura familiar observa-se a importância que o sistema de produção familiar possui para o ambiente. O equilíbrio dos agrossistemas e a promoção de ações de reaproveitamento de alimentos e dejetos de animais, por exemplo, refletem as possibilidades que um sistema sustentável pode impactar positivamente na sociedade, além das oportunidades no mercado brasileiro, quando observado o crescimento por produtos orgânicos nos últimos anos (Organis, 2020).

Como sugestões para abordagens futuras, mostra-se relevante analisar as políticas públicas e o contexto da sustentabilidade aplicada à agricultura familiar nos períodos atuais, observando-se as mudanças ocorridas em decorrência do cenário político-econômico nos últimos anos, os impactos setoriais e os comportamentos no consumo de alimentos.

\section{Referências}

Abramovay, R., \& Veiga, J. E. (1999). Novas instituições para o desenvolvimento rural: o caso do Programa Nacional de Fortalecimento da Agricultura Familiar (PRONAF). IPEA.

Albuquerque Neto, H. C., Marques, C. C., Furlanetto, E. L. (2008). A aplicação das dimensões do desenvolvimento sustentável e os níveis da competitividade sistêmica: O caso do arranjo produtivo de calçados de Campina Grande. In: Relatório Parcial do Programa Institucional de Bolsas de Iniciação Cientifica do CNPq.

Altieri, M. A. (2012). Agroecologia: bases científicas para uma agricultura sustentável. Expressão Popular, AS-PTA.

Associação de Promoção dos Orgânicos - Organis (2020). Seis meses de conquistas e desafios. https://organis.org.br/

Barbosa, G. S. (2008). O desafio do desenvolvimento sustentável. Revista Visões, 4(1), 1-11.

Brandenburg, A. (1999). Agricultura familiar, ONGs e desenvolvimento sustentável. Editora da UFPR.

Brasil. (2006). Lei n. 11.326 de 24 de julho de 2006a. Estabelece as diretrizes para a formulação da Política Nacional da Agricultura Familiar e Empreendimentos Familiares Rurais. Diário Oficial da União.

Brasil. (2012). Lei $N^{o} 12.651$, de 25 de Maio de 2012. Dispõe sobre a proteção da vegetação nativa: Diário Oficial da União. 
Brasil. (2012). Programa de Aquisição de Alimentos da Agricultura Familiar: renda para quem produz e comida na mesa de quem precisa. MDA: Brasília.

Comissão Mundial sobre o Meio Ambiente e Desenvolvimento. (1988). Nosso Futuro Comum. Fundação Getúlio Vargas.

Costa, M. B. B., Souza, M., Júnior, V. M., Comin, J. J. \& Lovato, P. E. (2015). Agroecologia no Brasil: 1970 a 2015. Agroecologia, $10(2), 63-75$.

Del Fiori, D. (2017). Agricultura familiar no estado de são paulo: caracterização e problemas. Nexos Econômicos, 10.

Del Grossi, M. E. \& Marques, V. P. M. A. (2010). Agricultura familiar no censo agropecuário 2006: o marco legal e as opções para sua identificação. Estudos Sociedade e Agricultura, 18(1), 127-157.

Delgado, G. C. (1997). Capital financeiro e agricultura no Brasil - 1965-1985. INCONE/UNICAMP.

Delgado, N. D. \& Romano, J. O. (1999). Sistemas agrários, atores sociais e construção de políticas públicas alternativas para o desenvolvimento rural local: o caso de Rebouças/PR. In: Costa, L. F. C., Moreira, R. J. \& Bruno, R. Mundo rural e tempo presente. Mauad.

Dias, R. (2011). Gestão ambiental responsabilidade social e sustentabilidade. Atlas S.A.

Dias, T. F., Nunes E. M., Torres, F. L., \& Torres, A. C. M. (2013). Programa de Aquisição de Alimentos da Agricultura Familiar (PAA) como estratégia de inserção socioeconômica: o caso do Território da Cidadania Sertão do Apodi (RN). Revista Brasileira de Gestão e Desenvolvimento Regional, 9(3).

Fundo Nacional de Desenvolvimento da Educação. (2009). Resolução/CD/FNDE $n^{\circ}$ 38, de 16 de julho de 2009.

Garcia, D. S. S. (2011). El principio de sostenibilidad y los puertos: a atividade portuária como garantidora da dimensão econômica da sustentabilidade. Tese (Doctorado en Derecho Ambiental y sostenibilidad), Universidad de Alicante.

Goodman, D. (2017). Espaço e lugar nas redes alimentares alternativas: conectando produção e consumo. In: Gazolla, M. \& Schneider, S. Cadeias curtas e redes agroalimentares alternativas: negócios e mercados da agricultura familiar.: Editora da UFRGS.

Grisa, C., Schmitt, C. J., Mattei, L. F., Maluf, R. S. \& Leite, S. P. (2011). Contribuições do Programa de Aquisição de Alimentos à segurança alimentar e nutricional e a criação de mercados para a agricultura familiar. Revista Agriculturas, 8, 34-41.

Grisa, C. \& Zimmermann, S. A. (2015). Estado e sociedade civil na promoção da segurança alimentar e nutricional no Brasil: a construção do Programa de Aquisição de Alimentos (PAA). Agroalimentaria, 21.

Guimarães, R. P. (1998). Ater rizando una Cometa: indicadores territoriales de sustentabilidad. CEPAL/ILPES.

Gusmão, Y. J. P. (2019). Agroextrativismo, comunidades tradicionais e os desafios na comercialização dos produtos: Januária, Norte de Minas Gerais. Dissertação (Mestrado) - Instituto de Ciências Agrárias, Universidade Federal de Minas Gerais, Brasil. 82p.

IBGE (2017). Censo Agropecuário. www.ibge.gov.br

IBGE. Censo Agropecuário 2006. https://ww2.ibge.gov.br/home/estatistica/economia/agropecuaria/censoagro/agri_familiar_2006.

Lindsey, T. C. (2011). Sustainable principles: common values for achieving sustainability. Journal Cleaner Production, 19(5), 561-565.

Martins, M. F. (2008). A influência dos índices de desenvolvimento sustentável na competitividade sistêmica: Um estudo exploratório no arranjo produtivo local de confecções em Campina Grande. Dissertação (Mestrado) - Universidade Federal da Paraíba. Brasil.

Moldan, B., Janoušková, S. \& Hak, T. (2012). How to understand and measure environmental sustainability. Indicators and targets. Ecological Indicators. $17,4-13$.

Neder, H. D. (2014). Trabalho e Pobreza Rural no Brasil. In: Buainain, A. M., Alves, E., Silveira, J. M. \& Navarro, Z. O Mundo Rural no Brasil do Século 21: A formação de um novo padrão agrário e agrícola. mbrapa.

Neves, M. F. \& Castro, L. T. E. (2010). Agricultura integrada: inserindo pequenos produtores da maneira sustentável em modernas cadeias produtivas. Atlas.

Oliveira, A. F. S. (2007). A sustentabilidade da agricultura orgânica familiar dos produtores associados à APOI (Associação dos Produtores Orgânicos da Ibiapaba-CE). Dissertação (Mestrado) - Universidade Federal do Ceará, Ceará, Brasil.

Ortega, A. C. (2008). Territórios deprimidos: desafios para as políticas de desenvolvimento rural. Campinas: Editora Alínea. Edufu.

Padua J. B., Schlindwein, M. M. \& Gomes, E. P. (2013). Agricultura familiar e produção orgânica: uma análise comparativa considerando os dados dos censos de 1996 e 2006. Interações, 14(2), 225-235.

Pereira, A. S., Shitsuka, D. M., Parreira, F. J., Shitsuka, R. (2018). Metodologia da pesquisa científica. UFSM.

Perez-Cassarino, J. (2013). Agroecologia, mercados e sistemas agroalimentares: uma leitura a partir da soberania e segurança alimentar e nutricional. In: Gomes, J. C. C. \& Assis, W. S. Agroecologia: princípios e reflexões conceituais. Embrapa.

Queiroz, S. F. (2012). Pronaf e desenvolvimento rural sustentável: uma análise econométrica espacial dos impactos do programa nas regiões sul e nordeste, do Brasil, entre 2000 e 2006. Tese (Doutorado) - Universidade Federal de Uberlândia, Uberlândia, Brasil.

Rabelo, L. S. \& Lima, P. V. P. S. (2007). Indicadores de sustentabilidade: a possibilidade da mensuração do desenvolvimento sustentável. Revista Eletrônica do Prodema, 1(1), 55-76. 
Research, Society and Development, v. 10, n. 4, e42310414220, 2021

(CC BY 4.0) | ISSN 2525-3409 | DOI: http://dx.doi.org/10.33448/rsd-v10i4.14220

Ribeiro, E. M. (2010). Histórias dos gerais. Belo Horizonte: UFMG.

Ribeiro, E. M. (2014). Produção e conservação de recursos na agricultura familiar dos gerais San franciscanos, semiárido de Minas Gerais. Rev. Econ. NE, 45 .

Romeiro, A. R. (2012). Sustainable Development: An Ecological Economics Perspective. Estudos Avançados, 26(74).

Sachs, I. (2009). Caminhos para o desenvolvimento sustentável. Rio de Janeiro: Garamond.

Salton, J.C., Mielniczuk, J., Bayer, C., Fabrício, A. C., Macedo, M. C. M. \& Broch, D. L. (2005). Matéria Orgânica do Solo na Integração LavouraPecuária em Mato Grosso do Sul / Dourados: Embrapa Agropecuária Oeste.

Santos, J. G. \& Cândido, G. A. (2013). Sustentabilidade e agricultura familiar: um estudo de caso em uma associação de agricultores rurais. Revista de Gestão Social e Ambiental, 7(1), 69-85.

Silva, L. F. (2007). Índice de Sustentabilidade Ambiental Agrícola (ISAGRI): uma proposta metodológica. Tese (Doutorado) - Universidade Estadual de Campinas, Campinas, Brasil.

Silva, T. C. \& Ferreira, P. R. (2016). O Programa de Aquisição de Alimentos sob a Ótica dos Atores Sociais Envolvidos. Desenvolvimento em Questão, 14(33), 301-329.

Siqueira, T. V. (2001). Desenvolvimento Sustentável: Antecedentes Históricos e Propostas para a Agenda 21. Revista do BNDES, 8(15), $247-288$.

Soriano, J. C. (2010). Apresentação. In. Ferment, G., Fernandes, G. \& Avanci, J. Seminário sobre proteção da agrobiodiversidade e direito dos agricultores: Propostas para enfrentar a contaminação transgênica do milho. Brasília: MDA.

Souza Filho, H. (2001). Desenvolvimento agrícola sustentável. In: Batalha, M. O. Gestão agroindustrial. Atlas.

Souza-Esquerdo, V. F. \& Bergamasco, S. M. P. P. (2015). Políticas públicas para a agricultura familiar brasileira: um estudo sobre o Pronaf nos municípios do circuito das frutas-SP. Revista Extensão Rural, 22(1), 9-35.

Stepanyan, K., Littlejohn, A. \& Margaryan, A. (2013). Sustainable e-Learning: Toward a Coherent Body of Knowledge. Educational Technology \& Society, 16(2), 91-102.

Stoffel, J. A. \& Colognese, S. A. (2015). O desenvolvimento sustentável sob a ótica da sustentabilidade multidimensional. Revista da FAE, $18(2), 18-37$.

Szmrecsanyi, T. \& Ramos, P. (1997). O papel das políticas governamentais na modernização da agricultura brasileira. História Econômica do Brasil contemporâneo, 2, 227-250.

Waquil, P. D., Schneider, S., Filippi, E. E., Conterato, M. A. \& Specht, S. (2007). Avaliação de desenvolvimento territorial em quatro territórios rurais no Brasil. DF: Ministério do Desenvolvimento Agrário (MDA).

Yolles, M. \& Fink, G. (2014). The Sustainability of Sustainability. Business Systems Review, 3(2), 1-32.

Zanelli, F. V., Lopes, A. S., Cardoso, I. M., Fernandes, R. B. A. \& Silva, B. M. (2015). Intercâmbios agroecológicos: aprendizado coletivo. Informe Agropecuário: Agricultura Orgânica e Agroecologia, 36(287). 